\title{
NUMERICAL INVESTIGATION OF THE RETROFITTING INTERVENTIONS OF THE SAN BENEDETTO CHURCH COMPLEX IN FERRARA (ITALY) FROM A SEISMIC VULNERABILITY PERSPECTIVE
}

\author{
RAFAEL SHEHU ${ }^{1 *}$ \\ ${ }^{1}$ Department of Civil and Environmental Engineering (DICA) \\ Politecnico Di Milano, \\ Piazza Leonardo Da Vinci 32, 22133, Milan, Italy \\ e-mail: rafael.shehu@polimi.it
}

\begin{abstract}
The San Benedetto church complex is an iconic architectural heritage asset of Ferrara, an attractive small city in the North of Italy. This paper investigates two separate parts from the complex, respectively the church, and the bell tower. The construction of the church dates back in the XV century, and many modifications were carried through years. During the second world war the church was severely damaged and then was fully restored to the original design. The bell tower instead is a typical tower of northern Italy, notably inclined by $3^{\circ}$. In the last decade, severe earthquake sequences occurred in the nearby areas, and the occupancy and safety of the structures were compromised. Several observed damages impelled upgrading measures, and consequently, many different retrofitting interventions got executed. Advanced numerical simulations are conducted in order to estimate the seismic vulnerability of each structure, by means of non-linear dynamic analysis. A critical historical evolution of the structure is considered, and two models for each structure are conceived respectively. The church models consist of 1) post-war reconstruction modeled with two distinct materials; 2) post-earthquake intervention with repointing technique and composites. The bell towers models consist of 1) the non-retrofitted tower; 2) the model with steel hooping bars. A comparative analysis is carried out based on the numerical results highlighting the pros and cons of each modeling technique and the efficiency of each intervention. Structural stiffening incorporated with a non-uniform distribution of the resisting capacities of the load-bearing elements highlights the seismic vulnerabilities. The necessity for the advanced numerical simulation emerges by the evidenced vulnerabilities in the performed simulations concerning the overall structural safety.
\end{abstract}

Keywords: Masonry Structures, Seismic Vulnerability, Seismic Analysis, Retrofitting

\section{INTRODUCTION}

The conservation and preservation of cultural heritage are a topic of great interest in seismicprone regions, such as Italy [1-4]. Recent earthquakes in the Italian territory (Umbria-Marche 1997, L'Aquila 2009, Emilia 2012, Central Italy 2016) highlighted the vulnerability of old masonry constructions to seismic excitations $[5,6]$. In particular, historical masonry churches 
proved to be highly vulnerable against horizontal loads [7-9]. Post-earthquake damage surveys carried out after past seismic events highlighted that one of the main causes of vulnerability for such structures is associated with local failure modes, mainly due to the out-of-plane response of macro-elements $[10,11]$.

It is a prevailing opinion, based upon vast research on their structural performance, that the masonry towers are relatively very vulnerable against seismic loads, $[12,13]$. The low tensile strength characterizes the masonry material and it is a paramount aspect that causes severe damages to occur. However, the mechanical properties are only one aspect of their vulnerability. Indeed, peculiar geometrical configurations, confinement with other constructions, the soil-structure interaction, or the inclination plays a relevant role in their performance [14-16].

This study is conceived as a comparative study between two different models of the church and the bell tower of the San Benedetto Complex. As will be detailed in the following paragraph, the studied structures represent complex futures, of geometry, materials and restoration interventions. All these aspects influence the seismic vulnerability thenceforth a detailed investigation is a step toward the knowledge of their actual safety level. Two models have been conceived in this study, corresponding to the state before and after the carried-out interventions. Non-linear dynamic analysis is the implemented numerical strategy to compare the seismic performance of the structures in terms of the induced damages. This study is a preliminary estimation of the efficiency of structural strengthening.

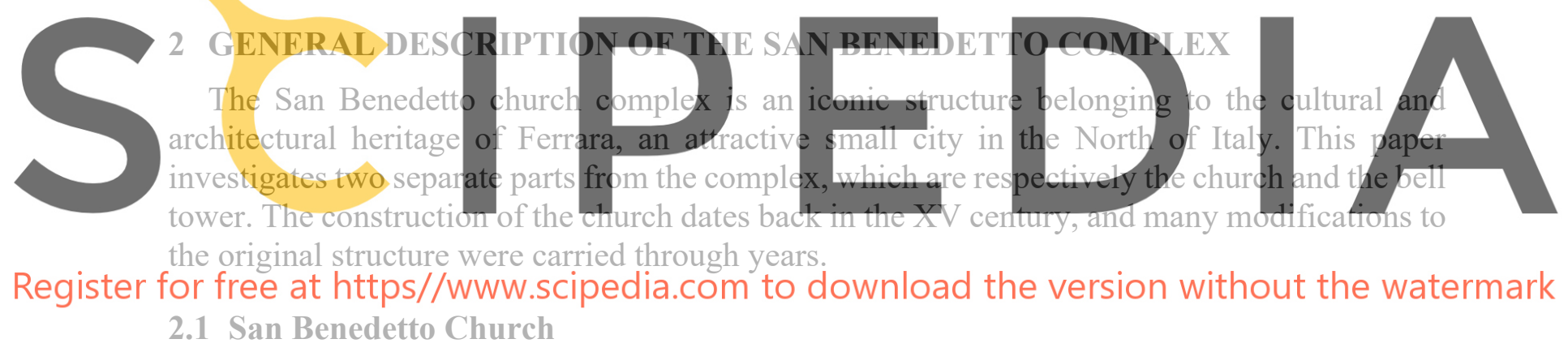

San Benedetto Abate Church in Ferrara was built between 1496 and 1553. During the Second War World, the church was severely damaged and partially destroyed, see Figure 1. A reconstruction process was performed according to the original drawings, and the works were completed in 1954. The overall length of the church is about $60 \mathrm{~m}$ and the height is almost 28 $\mathrm{m}$. The façade, which is subdivided into three parts by decorative pilasters and has a large rose window in the upper part. The church has the plan layout of a typical regular Latin cross with three naves. The naves are separated by two rows of columns, and along the aisles, there are six chapels in both sides symmetrically. The nave walls are approximately $18 \mathrm{~m}$ high and present a circular opening of diameter equal to $2.4 \mathrm{~m}$ at about mid-length. The aisles' walls are $11 \mathrm{~m}$ high, while each side chapel is $8 \mathrm{~m}$ high and presents high window openings. The transept of the church is almost $45 \mathrm{~m}$ long and $18 \mathrm{~m}$ high similar to the nave. The nave and the transept are covered with barrel vaults reinforced with ribs. The end part of the church consists of a semicircular apse and two small side apses, which have the same dimensions as the side chapels of the naves. The apses and the transept have a radius of almost $6 \mathrm{~m}$, two elongated windows at the end and two infilled circular windows aside. 


\subsection{San Benedetto Bell Tower}

The bell tower of San Benedetto Church as construction is newer compared to the church. It was built in 1621 according to a design by Giovani Battista Aleotti. The main future is the slenderness and the inclination. The last one is typical for all the towers in Ferrara, but this tower is the highest and the most inclined one. The height of the tower is $54 \mathrm{~m}$, and the base width is $7.1 \mathrm{~m}$. The tower is highly irregular in the upper part. It is composed of a regular tube $(30 \mathrm{~m})$ in the lower zone, and two blocks in the belfry zone. The wall thickness varies from $130 \mathrm{~cm}$ at the base to $30 \mathrm{~cm}$ at the top. The present inclination is $3.0^{\circ}$ towards the West and $0.5^{\circ}$ towards the North. The inclination influence and the last earthquake has caused vertical cracks passing through the openings. An intervention consisting of horizontal steel bars placed for hooking effect along the height was carried out after the earthquake in 2012.

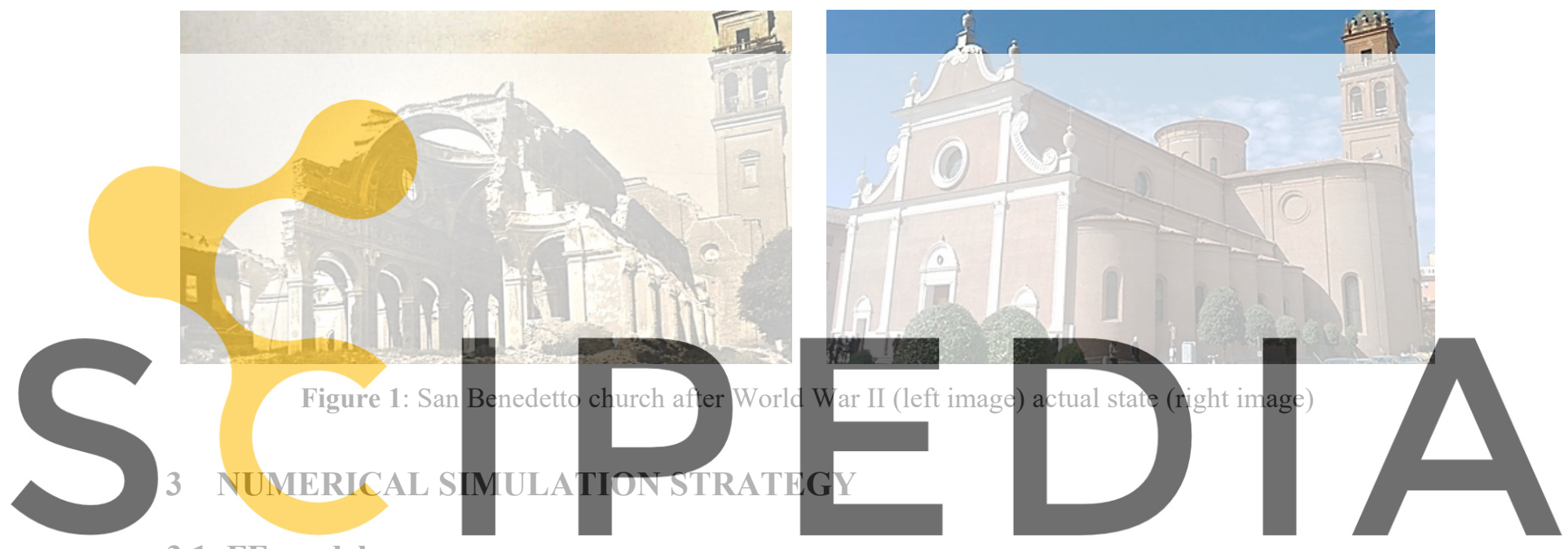

3.1 FE models

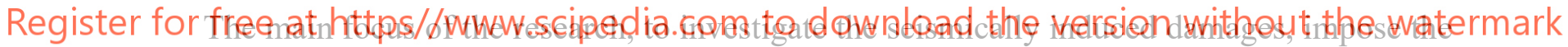
utilization of advanced numerical models. The literature offers different approaches towards the modeling of masonry structures where its heterogeneity is emphasized and crucial aspect, i.e. [10,17-19]. In order to mimic the non-linear behavior of the masonry material under seismic cyclic loads and characterizing the damage of the material, the Abaqus CAE software is used [20]. The constitutive modeling of masonry in the non-linear phase is approached according to a Concrete Damage Plasticity material model distinct damage parameter for compression and tension, [20]. The numerical models are discretized by means of tetrahedron elements that suit best for meshing any irregular shape. The characteristic length of the element is lower than $28 \mathrm{~cm}$ in all cases. Abaqus CAE automatically regularizes the fracture energy for each element based on its corresponding h parameter, [20]. As mentioned in the previous paragraph, both structures have undergone different retrofitting interventions. Herein, two different models are conceived, respectively representing the state before and after retrofitting. As depicted in Figure 1 , the church was rebuilt in approximately half of it. A simplified model, considering the old masonry material and the newly replaced one is implemented as depicted in Figure 3. In the absence of a detailed investigation of the material properties, a first investigation is made upon recommended parameters. For masonry constructions built with regular bricks and lime mortar, 
the Italian code recommends some reference values to be utilized during the analysis, provided in Table C8A.2.1, [21], while for the retrofitted material, by repointing or the undo-redo technique, the data of Table C8A.2.2 are combined with Table C8A.2.1 in order to obtain the mechanical properties. The Italian guideline CNR-DT215 [22], provides a reliable framework on how to design the retrofitting of existing structures using high-performance materials. According to those specifics, it is modeled the intervention of the vaults and dome with TRCM (textile reinforced cementitious matrix). While the vaults built with hollowed bricks are not modeled, A representative section of the structural elements is provided in Figure 2.

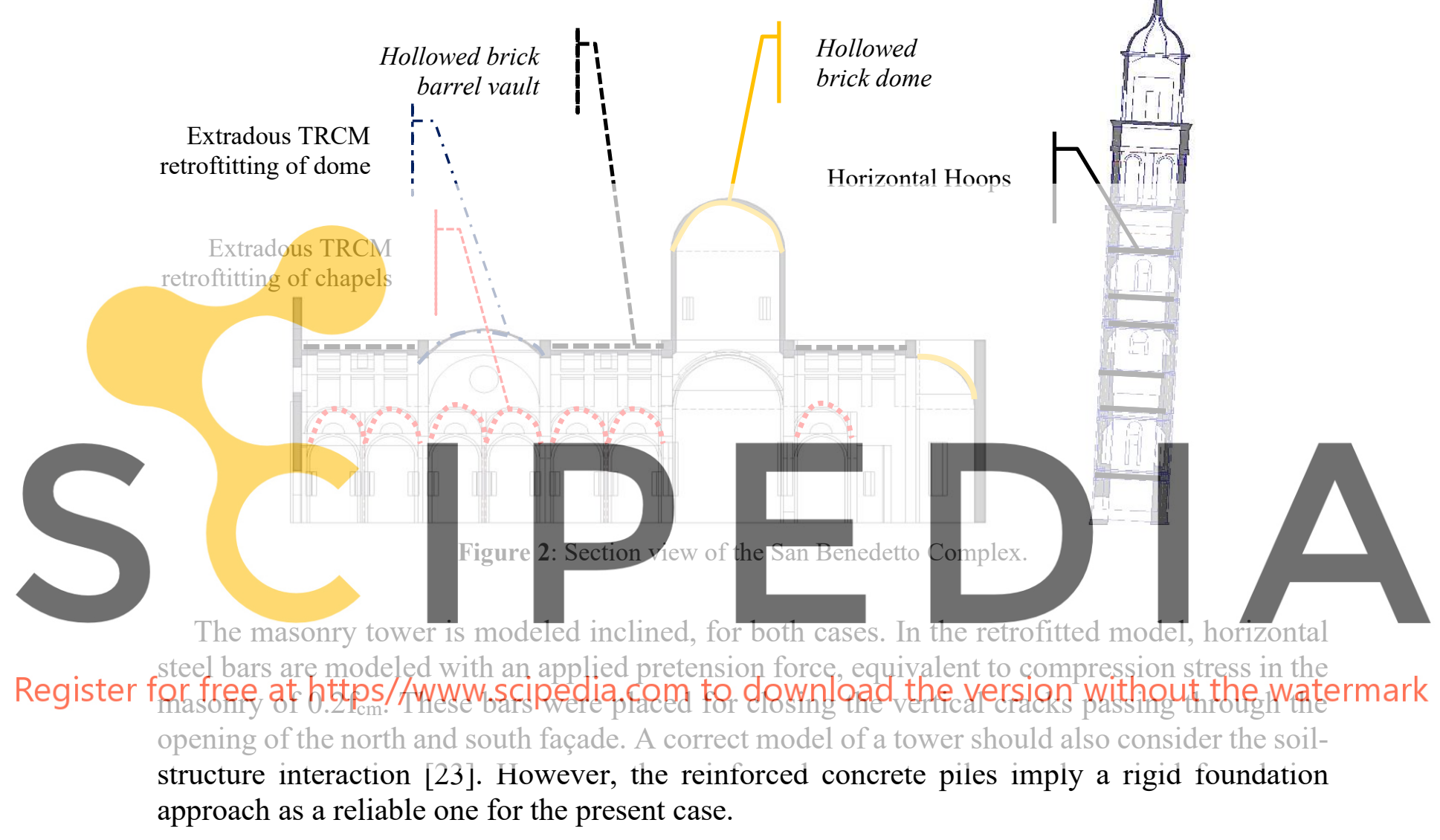

\subsection{Seismic analysis approach}

In the common practice of earthquake engineering, there are many strategies to address the verification of the limit states for any structure. Still, the highest accuracy is achievable by utilizing the non-linear dynamic analyses. Three real accelerograms are used instead, see Figure 4. Three real accelerograms obtained from Berkeley World Earthquakes Database (//ngawest2.berkeley.edu/), by inserting the characteristic response spectrums of Ferrara, are used. According to the Italian Code, the minimal number of pairs accelerograms to perform a seismic performance estimation is equal to three, and the worst output is taken as a referential response. The importance of the subjects imposes to verify the ultimate limit state of life safety with earthquakes compatible with a return period spectrum of 715 years. Such demand results to be very severe for masonry structures, thence, aiming to investigate the seismic vulnerability primary to a structural safety estimation, a return period of 475 years is chosen in this study. 

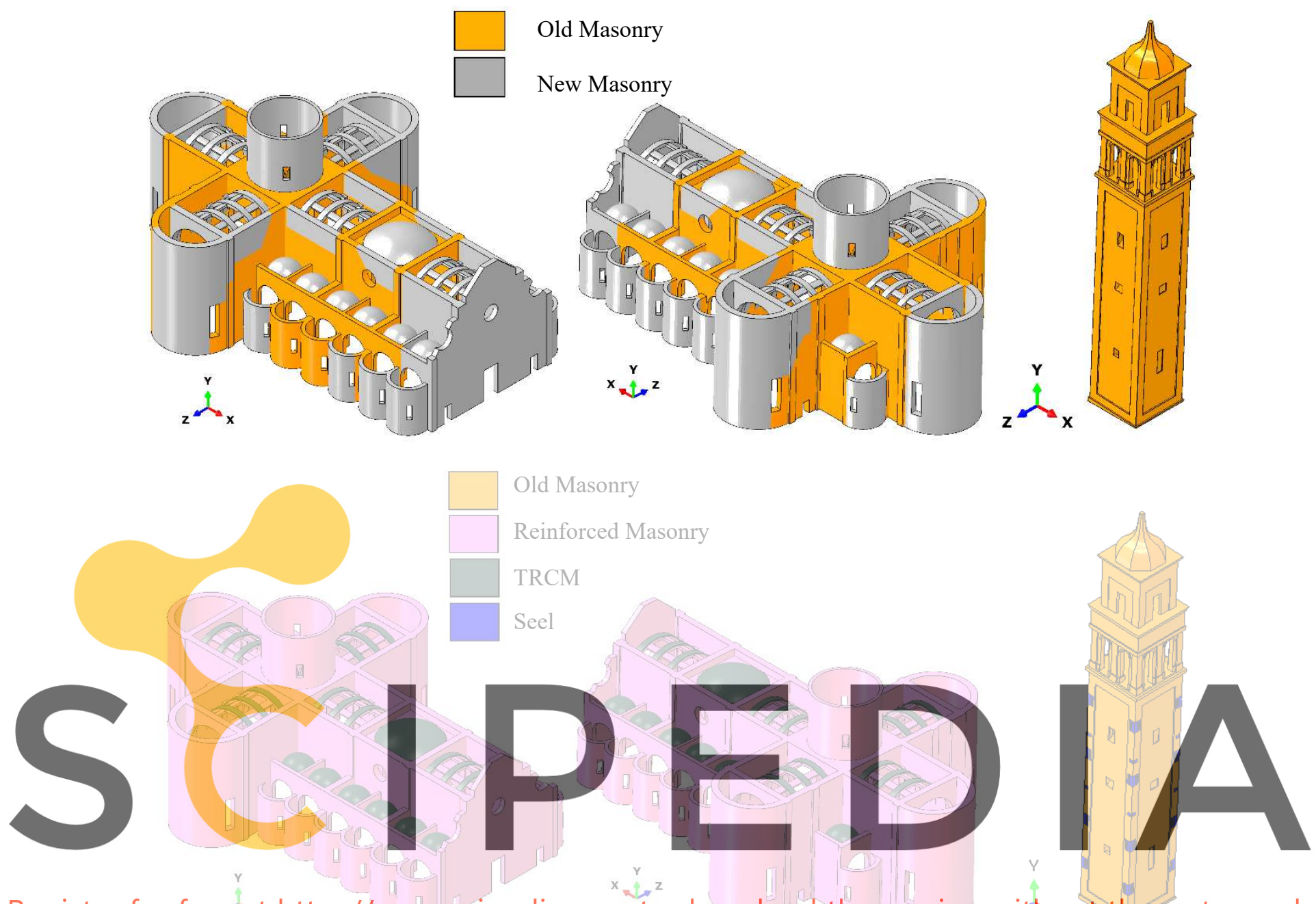

Register for free at https//www.scipedia.com to download the version withqut the watermark

Figure 3: 3D view of the models:-before intervention (upper image);-after interventions (lower images)
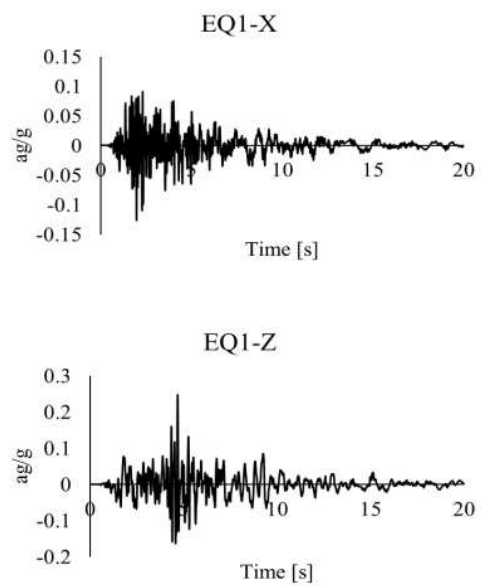

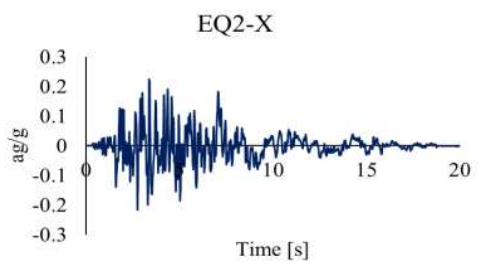

EQ2-Z

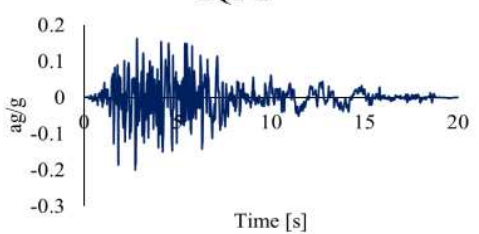

EQ3-X

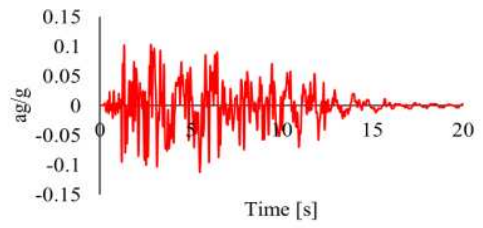

EQ3-Z

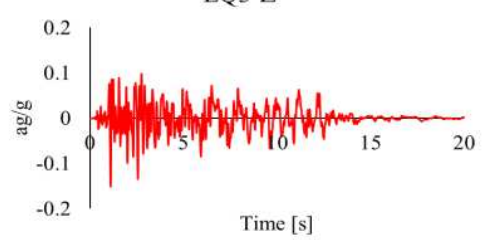

Figure 4: Horizontal components of the utilized accelerograms. 


\section{RESULTS}

In the followings images are depicted the induced seismic damage at the end of the seismic accelerograms prolonged for 30 seconds, as suggested by Eurocode 8, [24]. The damage parameter in tension is visualized. This parameter is an adequate approach for showing the initiation and the crack growth location for the concrete damage material. A relatively low value of the "h" parameter on the element's dimensions ensures a reliable result. Due to the acknowledged uncertainties and the role of accelerograms selection in the output results, the comparison among the models is made primarily in terms of qualitative results than quantitative ones. Also, it is well-known that the behavior of macroelements rules the vulnerability of masonry structures.

Figure 5 depicts the damage pattern for the church before the retrofitting. The diffusion of crack highlights some vulnerabilities, like severe damage of the interlocking between the chapels and the church, in the arches, or the intersection of the nave with the transept. It is worth noting that the traces of some damages follow the interface between the old masonry and the new texture. It highlights the relevance of the mechanical properties and the lack of homogeneity which brings to predefined failure surfaces which should be cured with special attention. The vault ribs result to be very vulnerable. Even though their structural relevance is negligible, its role in the operationality of the church and the aesthetic aspects is crucial.

The retrofitted church represents a lower level of seismic damage severity compared to the non-retrofitted church, as depicted in Figure 6. The vaults ribs are still prone to be damaged

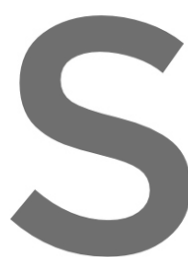
even they are retrofitted. highlighted is the scarce presence of this vulnerat Although substantial dar represents a similar level of the façade due to a detachment.
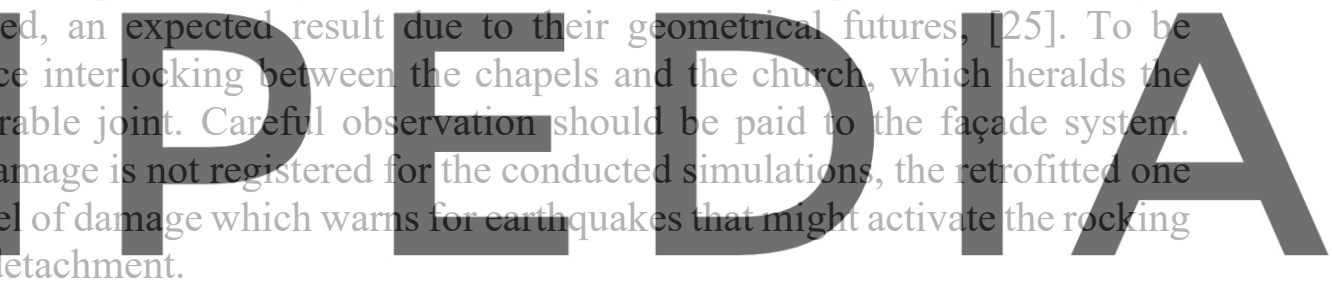

From a critical point of view, retrofitting has improved the seismic performance of the

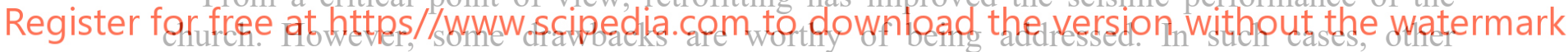

strengthening strategies like tie rods could help transform the structural system into a safer one. It could be a good motivation to investigate if such elements would not result in efficient ones, as likely occurred to be those applied to the tower.

Figure 7 and Figure 8 summarizes the registered damages for the non-retrofitted and retrofitted tower, respectively. At first glance, they represent the same picture, and it can be concluded that in terms of vulnerability, the present retrofitting does not provide a relevant contribution. The role of hooping steel rods into the incremented towers' capacity to withstand horizontal loads is not reflected.

Due to the slenderness and the inclination, the base of the structure and the belfry are very exposed to possible damages. The inclination has imposed the damage formation only on the tension side of the tower. 


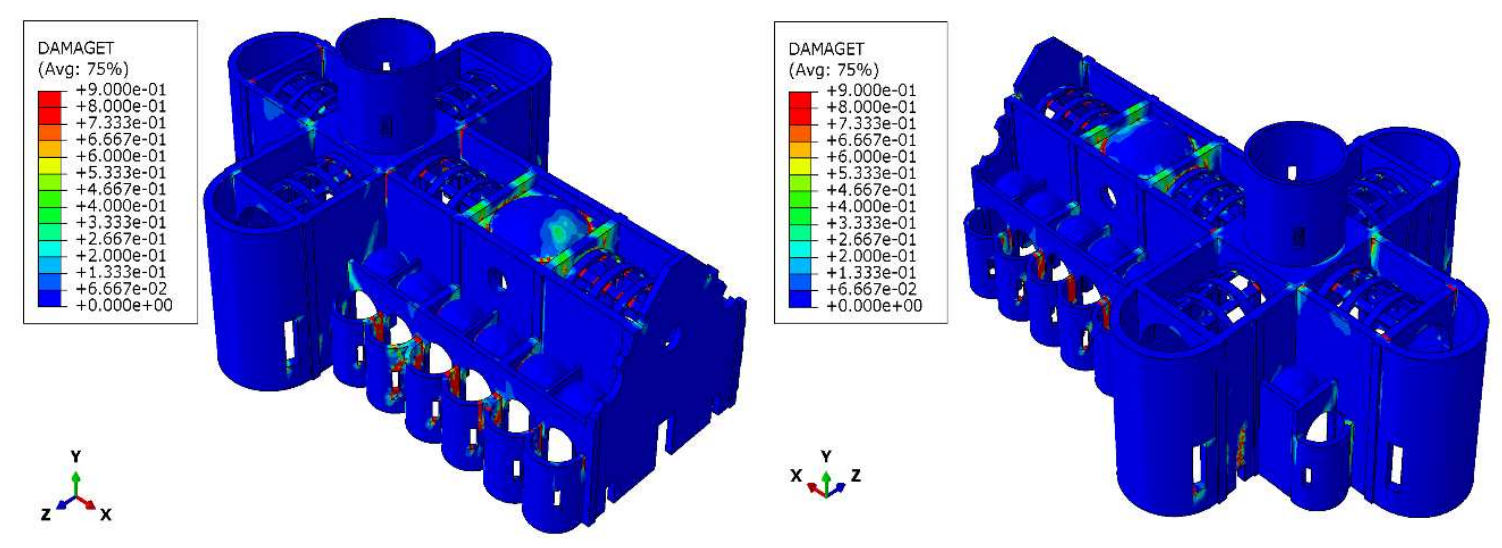

Earthquake 1
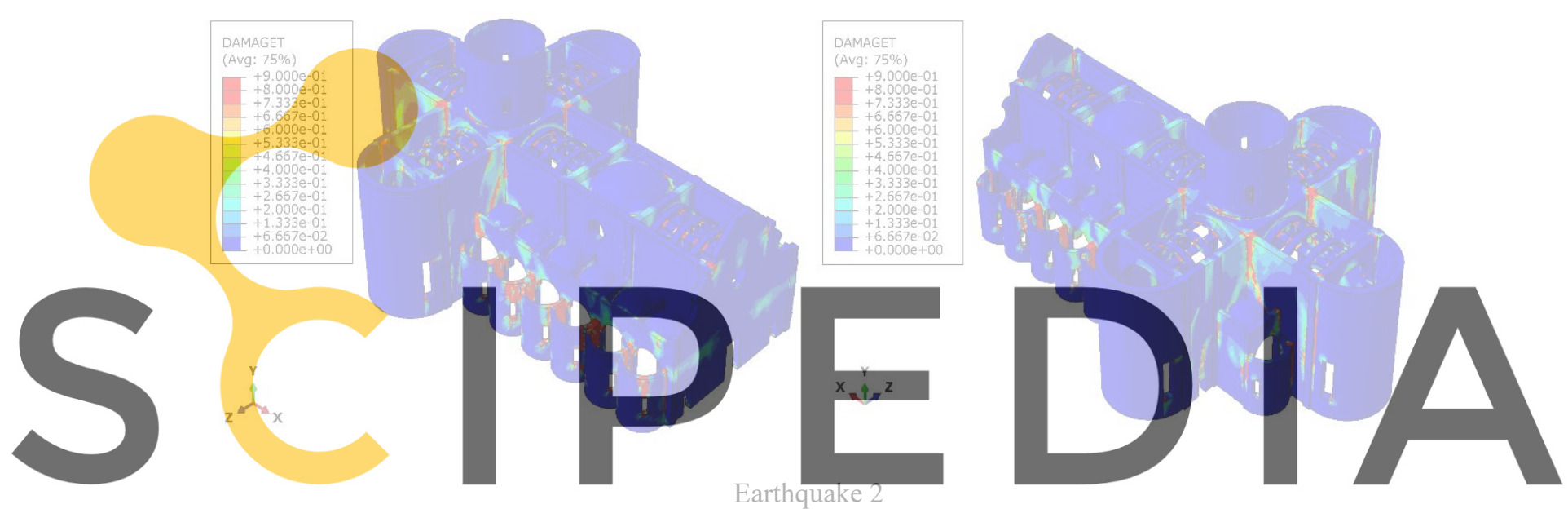

Register for free at https//wwW.scipedia.com to download the version without the watermark
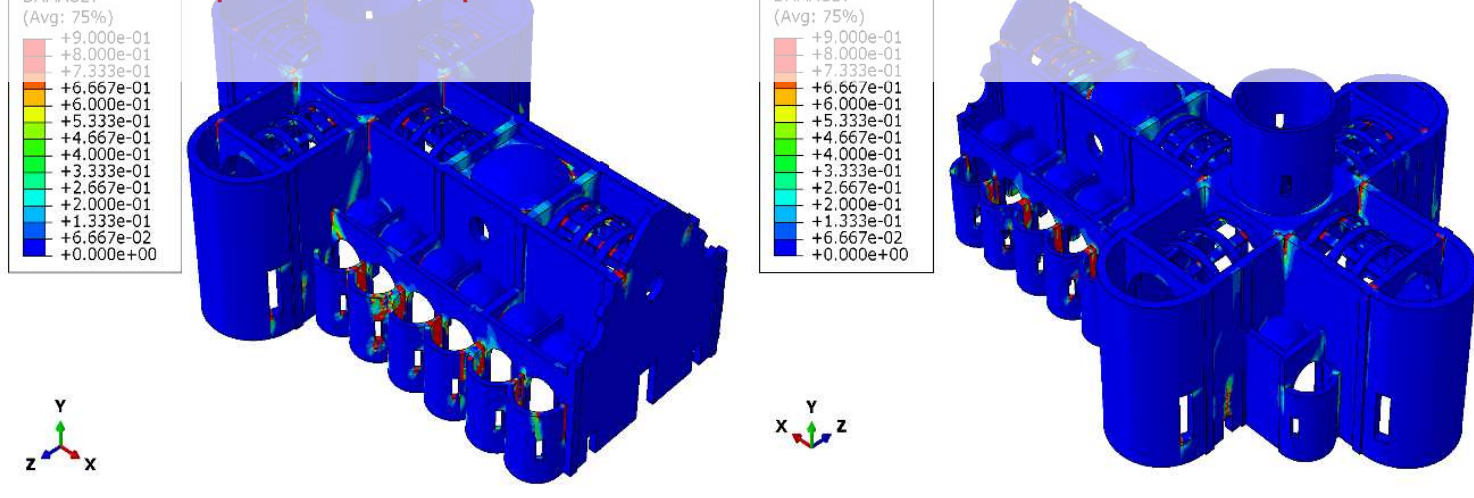

Earthquake 3

Figure 5: Seismically induced cracks in the church before retrofitting. 

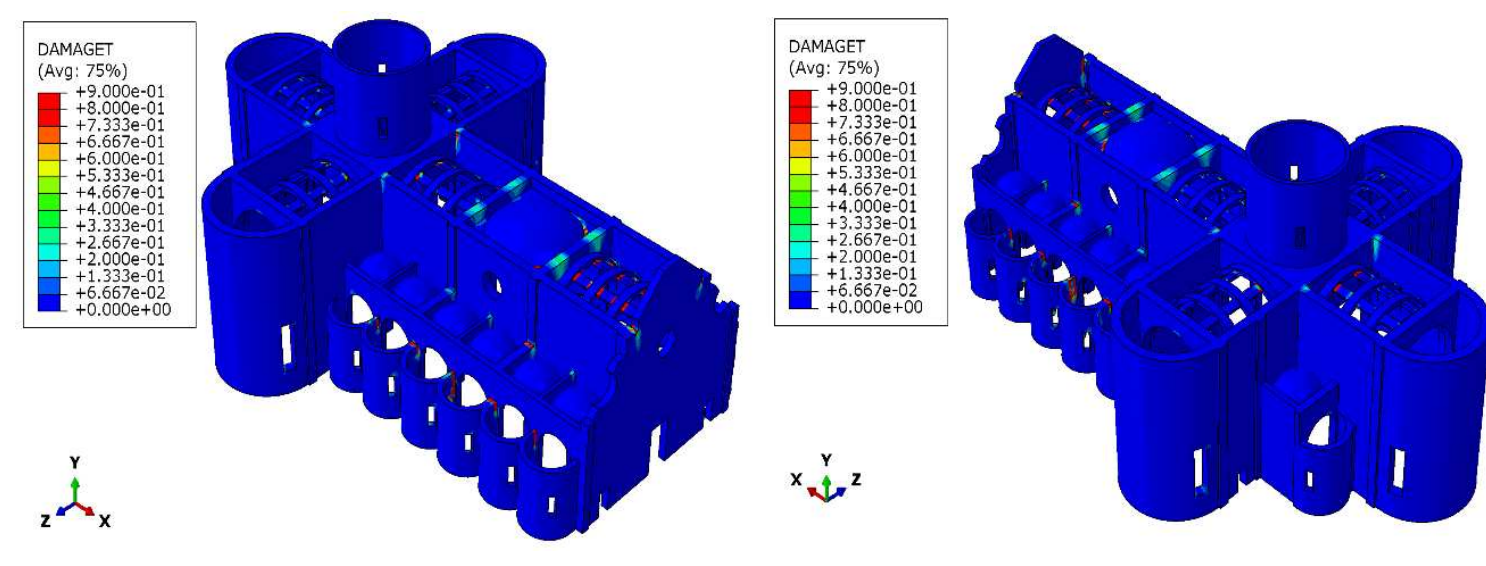

Earthquake 1
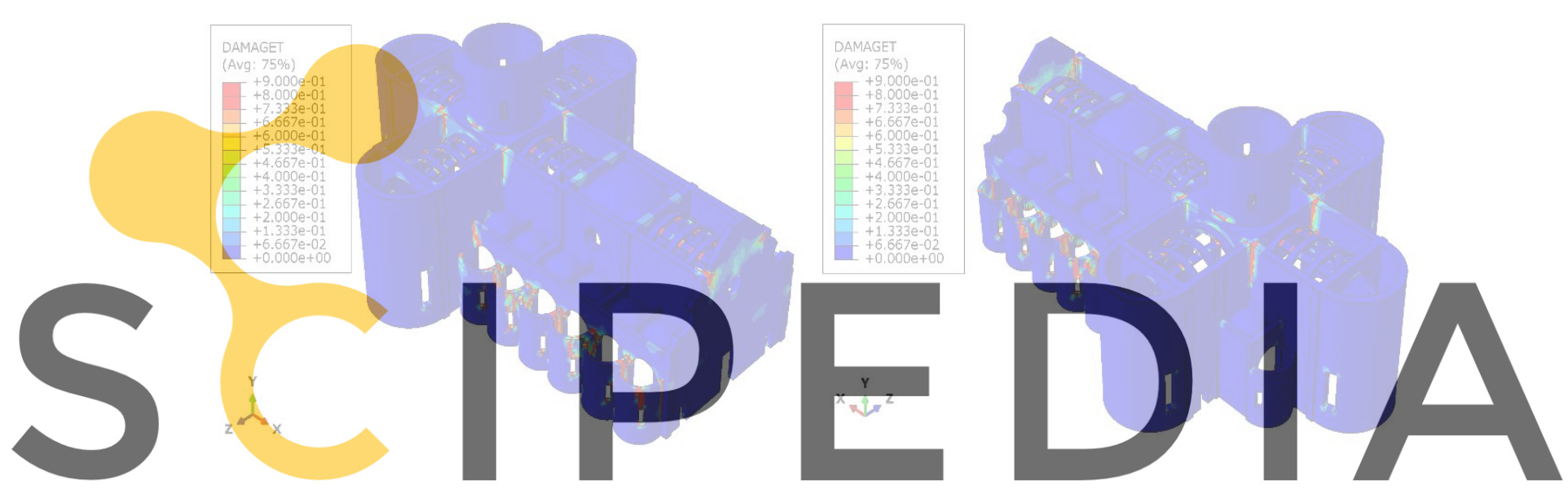

Earthquake 2

Register for free at https//www.scipedia.com to download the version without the watermark

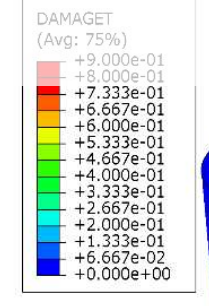

${ }_{z}^{\mathrm{r}}$
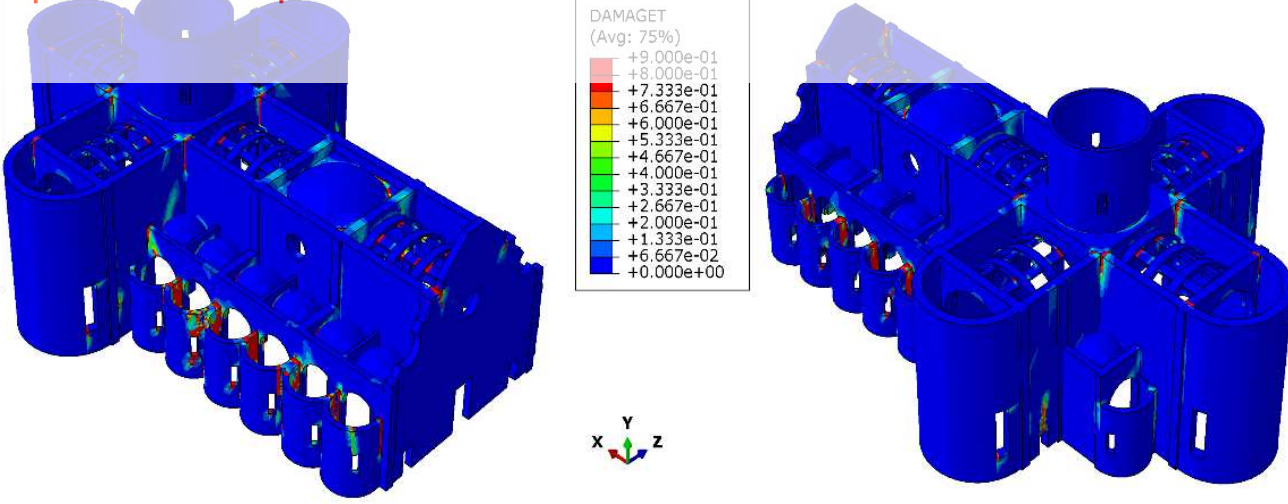

Earthquake 3

Figure 6: Seismically induced cracks in the church after retrofitting. 

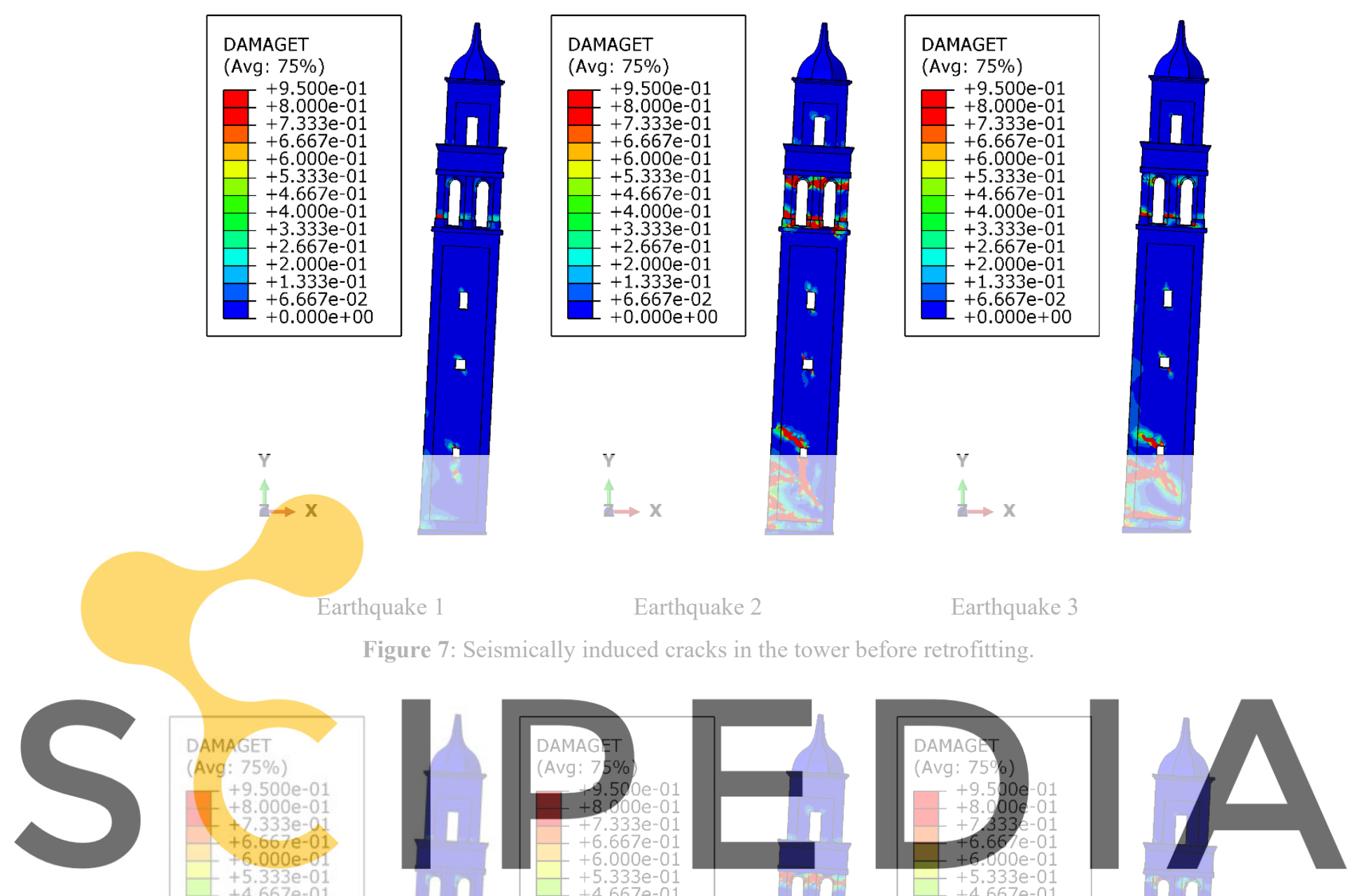

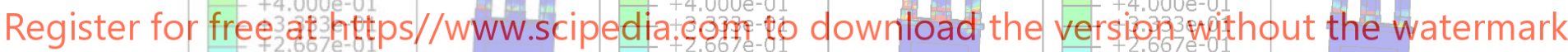
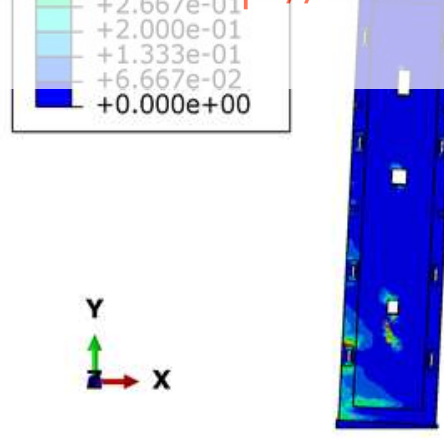

Earthquake 1
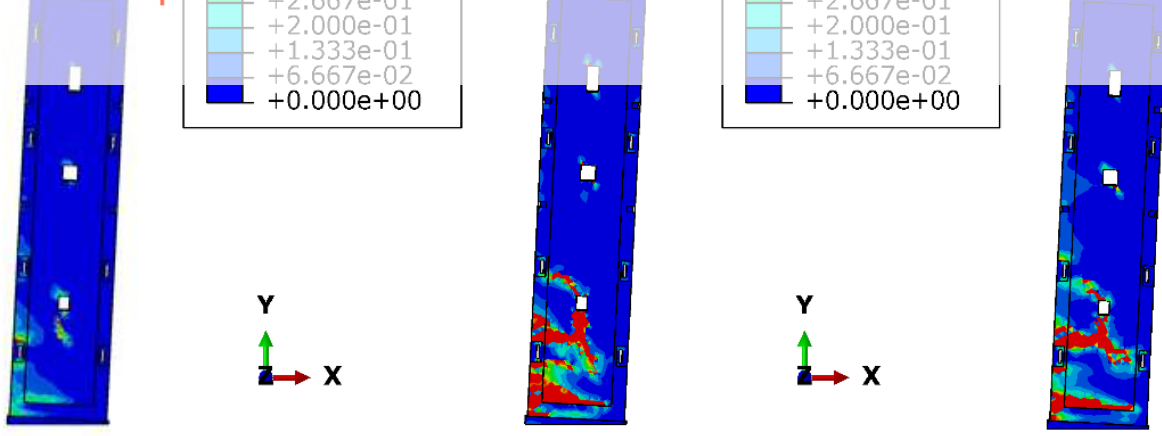

Figure 8: Seismically induced cracks in the tower after retrofitting.

\section{CONCLUSIONS}

This study provides a numerical insight into the seismic vulnerability and the effectiveness of retrofitting interventions for the San Benedetto's church and bell tower located in the 
province of Ferrara, Italy. The structures were retrofitted, by means of a post-seismic repairing of the damaged parts. Two different models were investigated and compared in terms of seismic performance and the role of retrofitting for each structure. Both structures were tested under the same level of seismic intensity. The bell tower, very slender and inclined, resulted to be more vulnerable compared to the church, a massive construction with high wall thicknesses.

The results showed some present challenges on the efficiency of retrofitting solutions. The bell tower was strengthened by horizontal steel bars which improved the interlocking of the walls and compacting the shaft; however the rocking at the base and the flexible belfry remain to be addressed in the future. The improved mechanical properties of the masonry for the church resulted in being quite effective. Despite that two issues should be faced. The first one is related to the quality of the intervention and the reliability of achieving such performance. The second one is related to the upgrade of the structural towards a less vulnerable one.

\section{REFERENCES}

[1] L. Binda, C. Modena, F. Casarin, F. Lorenzoni, L. Cantini, S. Munda, Emergency actions and investigations on cultural heritage after the L'Aquila earthquake: The case of the Spanish Fortress, Bull. Earthq. Eng. (2011). doi:10.1007/s10518-010-9217-3.

[2] A. Borri, M. Corradi, G. Castori, A. De Maria, A method for the analysis and classification of historic masonry, Bull. Earthq. Eng. 13 (2015) 2647-2665. doi:10.1007/s10518-015-9731-4.
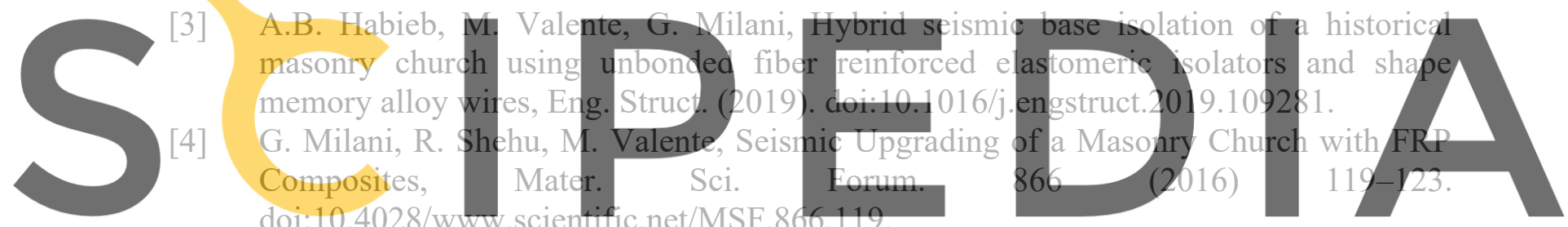

doi:10.4028/www. scientific.net/MSF.866.119.
F. Mollaioli, O. AlShawa, L. Liberatore, D. Liberatore, L. Sorrentino, Seismic demand

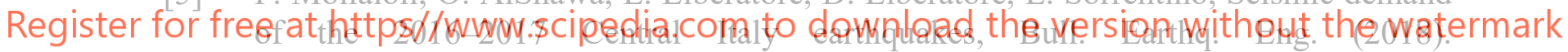
doi:10.1007/s10518-018-0449-y.

[6] M. Acito, E. Magrinelil, G. Milani, S. Tiberti, Seismic vuinerability of masonny buildings: Numerical insight on damage, J. Build. Eng. (2019) 101081. doi:10.1016/j.jobe.2019.101081.

[7] M. Valente, G. Milani, Seismic response and damage patterns of masonry churches: Seven case studies in Ferrara, Italy, Eng. Struct. 177 (2018) 809-835. doi:10.1016/j.engstruct.2018.08.071.

[8] A. Aşıkoğlu, Ö. Avşar, P.B. Lourenço, L.C. Silva, Effectiveness of seismic retrofitting of a historical masonry structure: Kütahya Kurşunlu Mosque, Turkey, Bull. Earthq. Eng. (2019). doi:10.1007/s10518-019-00603-6.

[9] L. Sorrentino, L. Liberatore, L.D. Decanini, D. Liberatore, The performance of churches in the 2012 Emilia earthquakes, Bull. Earthq. Eng. 12 (2014) 2299-2331. doi:10.1007/s10518-013-9519-3.

[10] P. Roca, M. Cervera, G. Gariup, L. Pela, Structural analysis of masonry historical constructions. Classical and advanced approaches, Arch. Comput. Methods Eng. 17 (2010) 299-325. doi:10.1007/s11831-010-9046-1. 
[11] S. Casolo, S. Neumair, M.A. Parisi, V. Petrini, Analysis of seismic damage patterns in old masonry church facades, Earthq. Spectra. $16 \quad$ (2000) 757-773. doi:10.1193/1.1586138.

[12] V. Sarhosis, G. Milani, A. Formisano, F. Fabbrocino, Evaluation of different approaches for the estimation of the seismic vulnerability of masonry towers, Bull. Earthq. Eng. (2017). doi:10.1007/s10518-017-0258-8.

[13] M. Shakya, H. Varum, R. Vicente, A. Costa, Seismic vulnerability assessment methodology for slender masonry structures, Int. J. Archit. Herit. 00 (2018) 1-30. doi:10.1080/15583058.2018.1503368.

[14] M. Valente, G. Milani, Effects of Geometrical Features on the Seismic Response of Historical Masonry Towers, J. Earthq. Eng. (2017) 1-33. doi:10.1080/13632469.2016.1277438.

[15] G. Milani, R. Shehu, M. Valente, Seismic vulnerability of leaning masonry towers located in Emilia-Romagna region, Italy:FE analyses of four case studies, AIP Conf. Proc. 1790 (2016) 130002. doi:10.1063/1.4968720.

[16] G. Milani, R. Shehu, M. Valente, Seismic Assessment of Masonry Towers by Means of Non-linear Static Procedures, Procedia Eng. 199 (2017) 266-271. doi:10.1016/j.proeng.2017.09.022.

[17] P.B. Lourénço, R. De Borst, J.G. Rots, A plane stress softening plasticity model for orthotropic materials, Int. J. Numer. Methods Eng. 40 (1997) 4033-4057. doi:10.1002/(SICI)1097-0207(19971115)40:21<4033::AID-NME248>3.0.CO;2-0.

[18] L. Gambarotta, S. Lagomarsino, Damage Models for the Seismic Response of Brick Masonry Shear Walls. Part II: the Continuum Model and Its Applications, Earthq. Eng. Struct. Dyn. 26 (1997) 441-462. doi:10.1002/(SICI)1096-9845(199704)26:4<441::AIDEQE651>3.0.CO;2-0.

[19] S. Lagomarsino, A. Penna, A. Galasco, S. Cattari, TREMURI program: An equivalent frame model for the non-linear seismic analysis of masonry buildings, Eng. Struct. 56 (2013) 1787-1799. doi:10.1016/j.engstruct.2013.08.002.

[20] D.S. Simulia, Abaqus 6.14 documentation, (2014).

[21] NTC, Aggiornamento delle "Norme Tecniche per le Costruzioni" - NTC 2018, Italy, 2018.

[22] CNR-DT 215, Istruzioni per la Progettazione, 1'Esecuzione ed il Controllo di Interventi di Consolidamento Statico mediante l'utilizo do Compositi Fibrorinforzati a Matrice Inorganica, 2018.

[23] S. Casolo, V. Diana, G. Uva, Influence of soil deformability on the seismic response of a masonry tower, Bull. Earthq. Eng. 15 (2017) 1991-2014. doi:10.1007/s10518-0160061-y.

[24] EC-8-P-1, Eurocode 8 : Design of structures for earthquake resistance - Part 1, 2014.

[25] G.L. Stockdale, V. Sarhosis, G. Milani, Seismic capacity and multi-mechanism analysis for dry-stack masonry arches subjected to hinge control, Bull. Earthq. Eng. (2020). doi:10.1007/s10518-019-00583-7. 